\title{
Combine harvester instrumentation system for use in precision agriculture
}

\begin{abstract}
A crop yield and field performance mapping system for New Holland TC-56 rice combine harvester $(\mathrm{RCH})$ for precision agriculture applications has been developed using LabVIEW. A Dewe-2010 PC data acquisition system has been used as a core unit to collect and store the real time field data from different sensors and a differential global positioning system to determine the exact latitude, longitude, and altitude of $\mathrm{RCH}$. Modular software allows programming flexibility in developed hardware. The spatial information has been measured and recorded in real time field testing. Sensors have been calibrated in a laboratory under specific conditions, and excellent measurement linearity has been obtained for most of parameters. The crop and yield performance maps have been obtained in real time from the field tests conducted in Malaysia. These maps will be used in precision agriculture to improve areas of low yield and to improve productivity of rice.
\end{abstract}

Keyword: Data acquisition system; LabVIEW software usage; Online control and monitoring system; Sensor application 